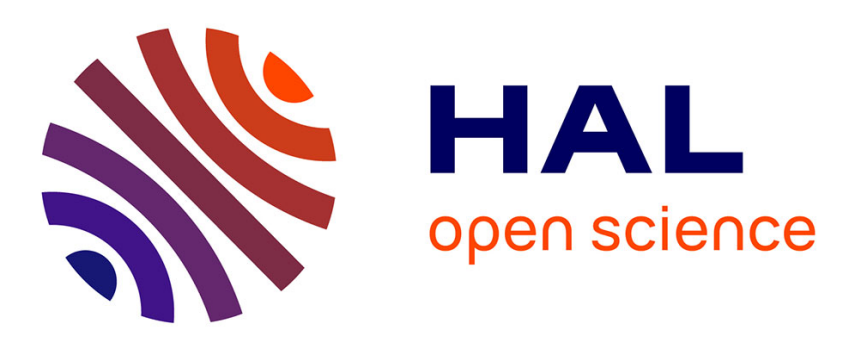

\title{
Comparison of GaN HEMTs Thermal Results through Different Measurements Methodologies: Validation with 3D Simulation
}

\author{
Anass Jakani, Raphaël Sommet, Florent Gaillard, Jean-Christophe \\ Nallatamby
}

\section{To cite this version:}

Anass Jakani, Raphaël Sommet, Florent Gaillard, Jean-Christophe Nallatamby. Comparison of GaN HEMTs Thermal Results through Different Measurements Methodologies: Validation with 3D Simulation. Thermal Investigations of ICs and Systems (THERMINIC), Sep 2021, Berlin, Germany. hal-03432574

\author{
HAL Id: hal-03432574 \\ https://hal.science/hal-03432574
}

Submitted on 17 Nov 2021

HAL is a multi-disciplinary open access archive for the deposit and dissemination of scientific research documents, whether they are published or not. The documents may come from teaching and research institutions in France or abroad, or from public or private research centers.
L'archive ouverte pluridisciplinaire HAL, est destinée au dépôt et à la diffusion de documents scientifiques de niveau recherche, publiés ou non, émanant des établissements d'enseignement et de recherche français ou étrangers, des laboratoires publics ou privés. 


\section{Comparison of GaN HEMTs Thermal Results through different measurements methodologies: Validation with 3D simulation}

*Note: Sub-titles are not captured in Xplore and should not be used

\author{
Anass JAKANI \\ CCSNL Team \\ XLIM laboratory \\ Brive-la-Gaillarde, France \\ anass.jakani@xlim.fr
}

\author{
Jean-Christophe NALLATAMBY \\ CCSNL Team \\ XLIM laboratory \\ Brive-la-Gaillarde, France
}

jean-christophe.nallatamby@xlim.fr

\author{
Raphael SOMMET \\ CCSNL Team \\ XLIM laboratory \\ Brive-la-Gaillarde, France \\ raphael.sommet@xlim.fr
}

\author{
Florent GAILLARD \\ CCSNL Team \\ XLIM laboratory \\ Brive-la-Gaillarde, France \\ florent.gaillard@unilim.fr
}

\begin{abstract}
In this work, thermoreflectance measurement technique is applied to GaN HEMTs transistors, GH15 8x50 $\mu \mathrm{m}$ and $6 \times 50 \mu \mathrm{m}$ from the UMS foundry. These measurements are compared to 3D simulation, but also to measurements based on an electrical approach we developed previously in [1]. The good agreement between results and the thermalization time constant proposed in [2] for GaN HEMTs validate finally all our approach dedicated to thermal resistance or thermal time constant
\end{abstract}

Keywords-Thermoreflectance, thermal impedance, GaN HEMT, thermal simulation

\section{INTRODUCTION}

The improvement of the GaN HEMT technology offers answers to the need for efficient solid-state operation at RF frequencies. However, self-heating can degrade the performance and reliability of the device by affecting the electron mobility in the channel. Hence, the knowledge of the temperature of the device under operating conditions and the location of the hot spot became mandatory in the RF electronic industry.

In our work, we propose a comparison between both an electrical and an optical method dedicated to temperature measurement. Concerning the electrical method our approach has been developed in [1] but other methods like [8] [9] can be also used. Concerning the optical method, we have chosen the thermoreflectance method and the Microsanj test setup for its ability to measure the temperature with a high spatial resolution ( $<1 \mathrm{um})$ and high time resolution( $<50 \mathrm{~ns})$. MicroRaman is reputed to offer also very good results [10]

\section{MethodS AND SETUP}

A. Thermoreflectance setup and measurement method

The reflectivity of the materiel changes when the temperature changes [3]. Thus, the relationship between the relative surface reflectance variation $\left(\Delta R / R_{0}\right)$ and the surface temperature for a given surface can be expressed:

$$
\frac{\Delta R}{R}=C_{t h} \cdot \Delta T
$$

$C_{t h}$ represents the TR coefficient which is a material parameter and wavelength of probing light dependent.
Typically, the spatial resolution of $365 \mathrm{~nm}$ is the best for $\mathrm{GaN}$ with SiNx passivation. The TR coefficient is obtained through a calibration process by putting the Device Under Test (DUT) on a thermal stage with two temperatures, hot $\left(50^{\circ} \mathrm{C}\right)$ and cold $\left(20^{\circ} \mathrm{C}\right)$. When the temperature changes, the reflectance also changes. This TR coefficient is controlled by a piezo stage for each point of CCD camera. Two types of measurement are possible with this test setup: steady state or transient temperature measurement. For the transient measurement the timing delay for measuring inside the excitation pulse is precisely controllable.

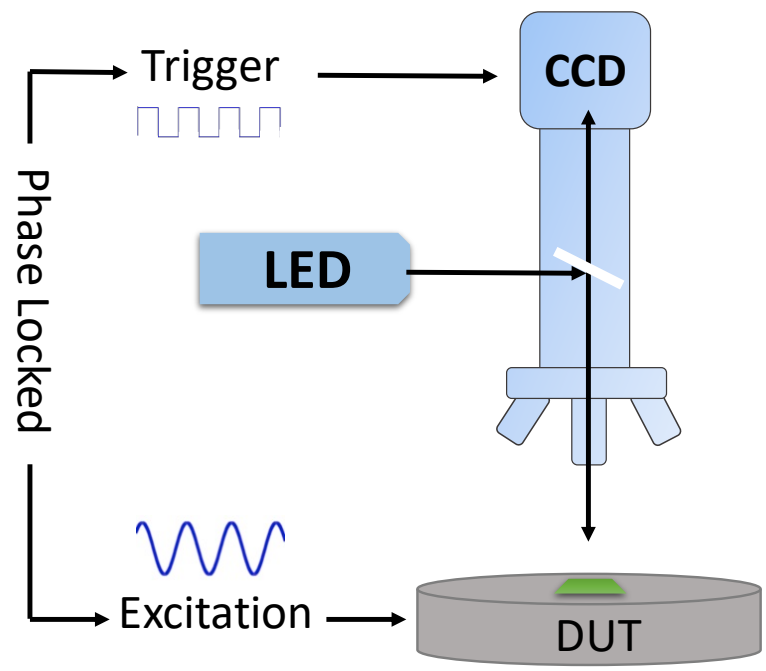

Figure 1: Thermoreflectance experimental setup

\section{B. $\quad$ Pulsed I-V measurement method}

Two steps are needs for this measurement: The first step consist in the calibration process. The quiescent point selected is $\mathrm{V}_{\mathrm{GSq}}=\mathrm{V}_{\mathrm{DSq}}=0 \mathrm{~V}$. We measure the pulsed I-V characteristics of the device for different thermal chuck temperatures from $25^{\circ} \mathrm{C}$ to $75^{\circ} \mathrm{C}$. We extract the on-state resistance from the slope of the linear region of the $\mathrm{I}(\mathrm{V})$ characteristics and we plot it as a function of the chuck temperature. In the second step, we fix the baseplate temperature to $25^{\circ} \mathrm{C}, \mathrm{V}_{\mathrm{GSq}}$ at $0 \mathrm{~V}$ and we vary $\mathrm{V}_{\mathrm{DSq}}$ from 0 to $10 \mathrm{~V}$, the device dissipates a different amount of DC power 
by self-heating effects. Thus, the Ron was measured as a function of dissipated power $\left(\mathrm{P}_{\text {diss }}\right)$. The thermal resistance can be determined by the ratio of the two slopes:

$$
R_{t h}=\left(\frac{\partial R_{O N}}{\partial P_{\text {diss }}}\right) /\left(\frac{\partial R_{O N}}{\partial T}\right)
$$

\section{GAN HEMT RESULTS AND DISCUSSION}

\section{A. Device description}

Measurements have been performed on a GH15 8x50 $\mu \mathrm{m}$ and $6 \times 50 \mu \mathrm{m}$ based on $\mathrm{AlGaN} / \mathrm{GaN}$ heterostructure grown on a $70 \mu \mathrm{m}$ thickness silicon carbide substrate $(\mathrm{SiC})$. The gate length $\mathrm{L}_{\mathrm{G}}$ is $0.15 \mu \mathrm{m}$.

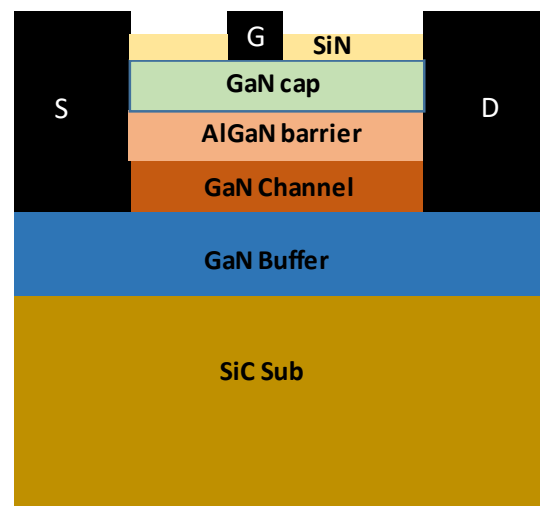

Figure 2: Cross section of the device structure

\section{B. Thermoreflectance measurement on GaN transistors}

In order to measure the temperature under the $\mathrm{SiNx}$ passivation where the 2-Dimentional Electron Gas is located and where also the peak value of temperature is localized, we use the $365 \mathrm{~nm}$ wavelength. Note that the illumination source chosen here is an incoherent dispersed low power UV LED in order to minimize the photoinduced current during the thermoreflectance measurement [4]. We use a $50 \mathrm{X}$ objective with $\mathrm{NA}=0.42$ resulting in a diffraction limited lateral spatial resolution of $\sim 0.3 \mu \mathrm{m}$. The thermoreflectance measured through the calibration process on the region of interest is $\left(C_{t h}=-3 \times 10^{-3} \pm\right.$ $\left.2 \times 10^{-5}{ }^{\circ} \mathrm{C}^{-1}\right)$. On the same region the thermoreflectance coefficient obtained respectively for 530nm (green) and $470 \mathrm{~nm}$ (blue) is $\left(C_{t h}=-2 \times 10^{-4}{ }^{\circ} \mathrm{C}^{-1}\right.$ and $C_{t h}=$ $\left.-7 \times 10^{-5}{ }^{\circ} \mathrm{C}^{-1}\right)$.

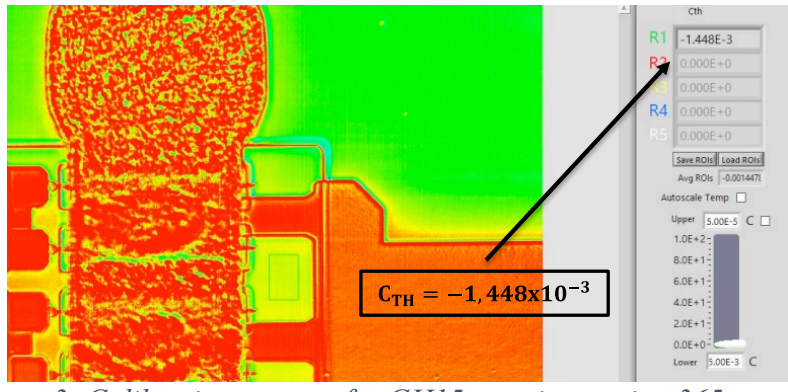

Figure 3: Calibration process for GH15 transistor using $365 \mathrm{~nm}$ $L E D$

So, the thermal coefficient for the UV signal is large enough to obtain accurate measurements results. We have performed two types of measurements for two device developments: a transient measurement for the GH15 $8 \times 50 \mu \mathrm{m}$ and a steady state one for a the GH15 6X50 $\mu \mathrm{m}$. For the transient measurement, the square wave pulse is used and the following pulse conditions are applied: pulse width $=100 \mu$ s and pulse period $=1 \mathrm{~ms}$. The bias condition chosen is $\mathrm{Vds}=7 \mathrm{~V}$ and $\mathrm{Ids}=100 \mathrm{~mA}$

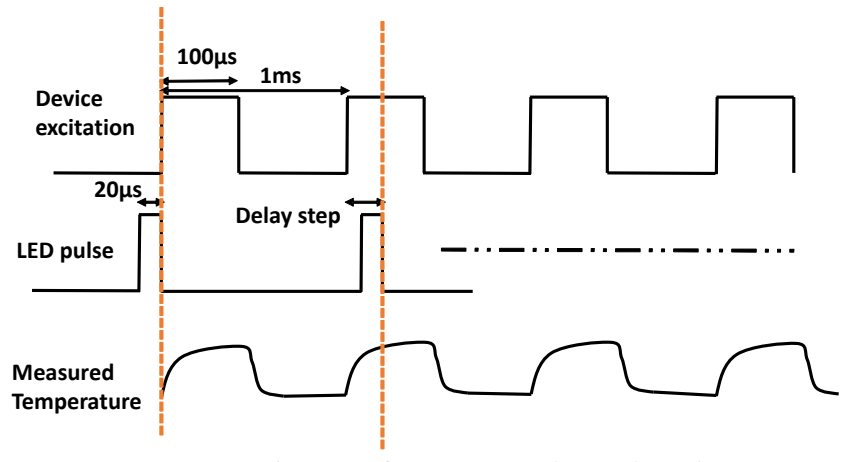

Figure 4: Timing diagram for transient thermal analysis

The measurement of the temperature variation leads to $\Delta \mathrm{T}=$ $22^{\circ} \mathrm{C}$. Then according to the dissipated power, we can extract the thermal resistance:

$$
R_{t h}=\frac{\Delta T}{P_{\text {diss }}}=31.4^{\circ} \mathrm{C} / \mathrm{W}
$$

Moreover, the time constant measured for the transient behavior is $\tau \simeq 40 \mu \mathrm{s}$ as shown in figure (5).

Bagnall [2] in his work, demonstrates that the longest 2Dthermal time constant can be expressed as:

$$
\tau=\frac{4 . L_{s u b}^{2}}{\pi^{2} \cdot \alpha}
$$

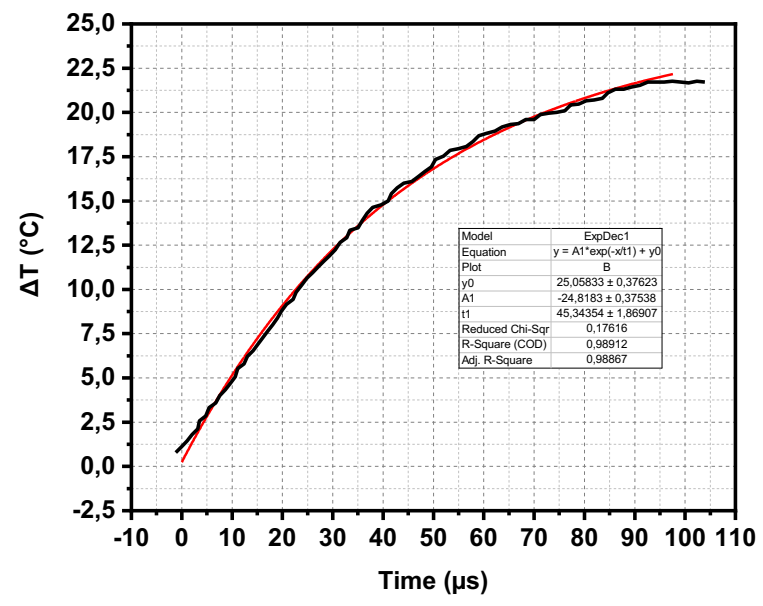

Figure 5: Transient temperature vs time for the $8 \times 50 \mu$ m device

Where $\alpha=\frac{K}{\rho . C_{p}}$ is thermal diffusivity, $\mathrm{L}_{\text {sub }}$ is the thickness of the substrate. In our case the thickness $\mathrm{L}_{\text {sub }}$ of the $\mathrm{SiC}$ substrate is $70 \mu \mathrm{m}$ and $\alpha=1.82 \times 10^{-4} \mathrm{~m}^{2} / \mathrm{s}$.

The thermal time constant calculated by this simple formula [2], gives $\tau=10.9 \mu \mathrm{s}$. We observe a difference of approximately $30 \mu \mathrm{s}$. This difference may be due to 
measurement conditions. (the width of the optical signal chosen for the TR measurement is $20 \mu$ s).

For the steady state measurement, the measured temperature variation is $\Delta T=27^{\circ} \mathrm{C}$ for a drain-source signal $\mathrm{Vds}=9 \mathrm{~V}$ and $I d s=70 m A\left(P_{\text {diss }}=0.63 \mathrm{~W}\right)$.

The measured thermal resistance in the region of interest is:

$$
R_{t h}=42.86^{\circ} \frac{C}{W}
$$

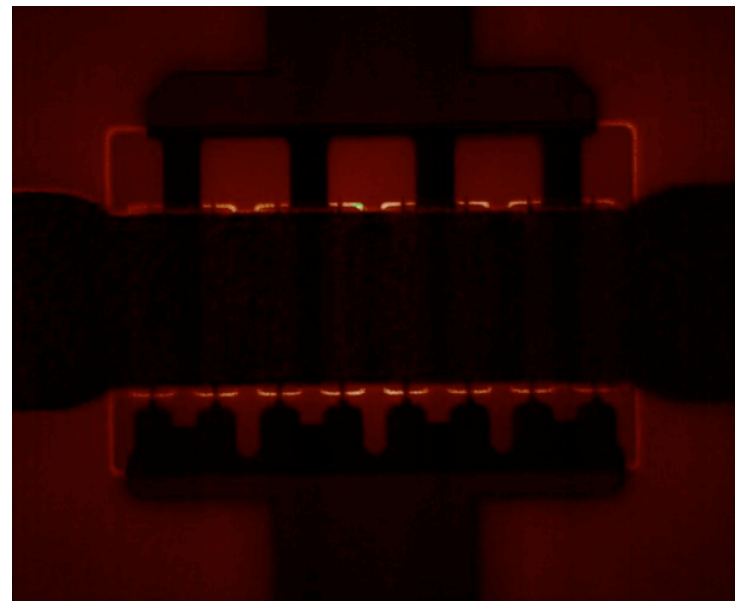

Figure 6: GH15 8x50um heated

\section{Pulsed I-V measurement to extract thermal resistance}

The method proposed in [1] is used to extract the thermal resistance $\left(\mathrm{R}_{\mathrm{TH}}\right)$ on a $\mathrm{GH} 156 \times 50 \mu \mathrm{m}$. Using the on-state resistor method described in II-B, the thermal resistance obtained for the GH15 $6 \times 50 \mu \mathrm{m}$ is $41.25^{\circ} \mathrm{C} / \mathrm{W}$. Similar

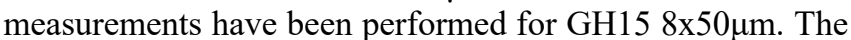
corresponding measurement results were previously published in [5] $\left(\mathrm{R}_{\mathrm{th}}=32.5^{\circ} \mathrm{C} / \mathrm{W}\right)$. The ratio between each thermal resistance is correlated to their finger number

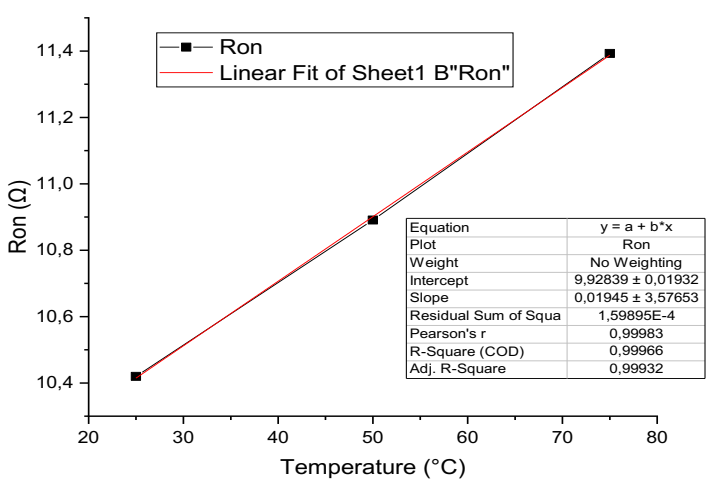

Figure 7: Ron at different temperatures for GH15 6x50

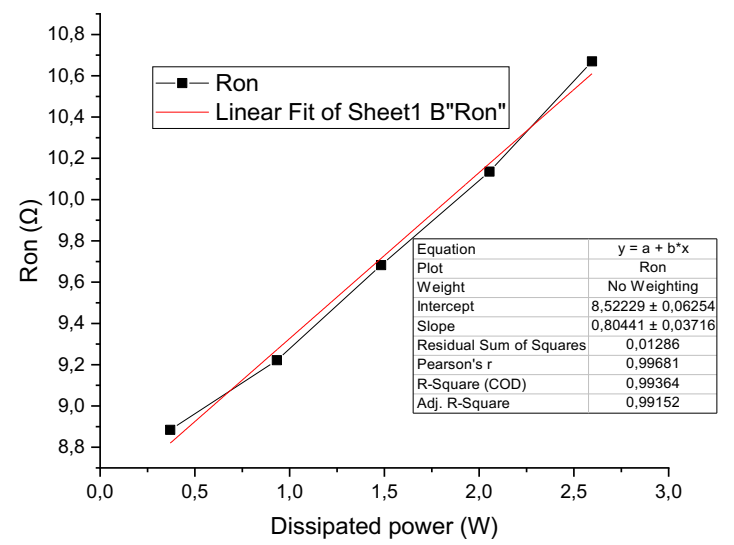

Figure 8: Ron at different dissipated power for GH15 6x50um

D. $\quad 3 D$ simulation using Salome-Meca software

\begin{tabular}{|c|c|c|c|c|}
\hline Material & $\begin{array}{l}\text { Thermal } \\
\text { conductivity } \\
(\mathbf{W} / \mathbf{m} . \mathbf{K})\end{array}$ & $\begin{array}{l}\text { Density } \\
\left(\mathrm{g} / \mathrm{m}^{3}\right)\end{array}$ & $\begin{array}{l}\text { Specific } \\
\text { heat } \\
\text { (J/K.g) }\end{array}$ & Nodes \\
\hline $\mathrm{SiC}$ & 390 & 0.665 & 3.21 & \multirow{5}{*}{211318} \\
\hline GaN & 130 & 0.431 & 6.15 & \\
\hline SiN & 35 & 0.68 & 3.2 & \\
\hline AlGaN & 40 & 0.604 & 5.184 & \\
\hline Au & 315 & 0.13 & 19.32 & \\
\hline
\end{tabular}

For the steady state simulation, the device structure of a $\mathrm{GH} 156 \times 50 \mu \mathrm{m}$ is symmetric with respect to $\mathrm{X}$-axis and $\mathrm{Y}$ axis and therefore quarter of the structure is used for the simulation. We consider adiabatic boundary condition on the area of the structure. We apply a dissipated power equal to $1 \mathrm{~W}$ on the quarter of the structure. The applied DC power is $29.63 \mathrm{~W} / \mathrm{um}^{2}$ per heat source. Figure 9 shows that the maximum temperature obtained in the channel is $\mathrm{T}_{\max }=196.2$ ${ }^{\circ} \mathrm{C}$ (for a baseplate temperature of $25^{\circ} \mathrm{C}$ so $\Delta \mathrm{T}=171.2^{\circ} \mathrm{C}$ ). Thus, the simulated thermal resistance for the GH15 $6 \times 50 \mu \mathrm{m}$ is $R_{t h}=42.8^{\circ} \mathrm{C} / \mathrm{W}$.

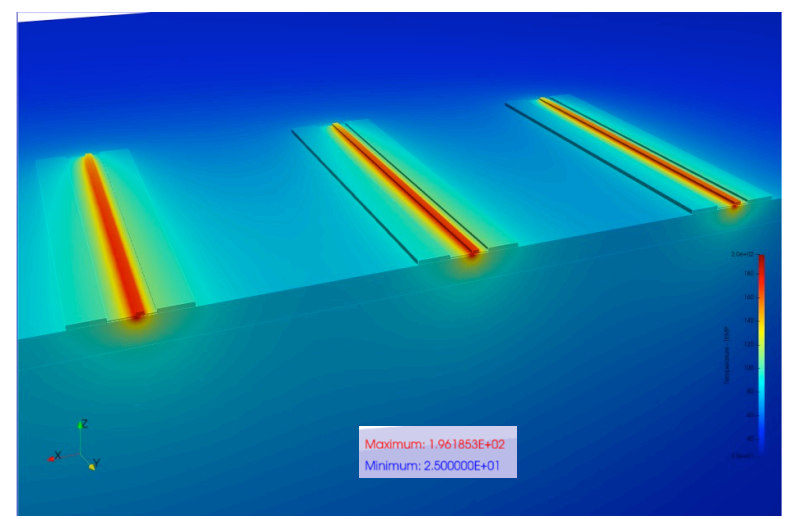

Figure 9: Steady state simulation for a 6x50 4 m device 
We perform also a transient simulation with the same boundary conditions as for the steady state simulation

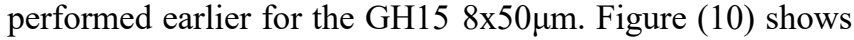
that the maximal temperature obtained in the channel which is $\mathrm{T}_{\max }=147.76{ }^{\circ} \mathrm{C}$ (for a baseplate of $25^{\circ} \mathrm{C}$ so $\Delta \mathrm{T}=$ $\left.122.76^{\circ} \mathrm{C}\right)$. The thermal resistance obtained through simulation is $R_{t h}=30.7^{\circ} \mathrm{C} / \mathrm{W}$ In order to determine the thermal time constant, we used the Foster thermal network to fit the data obtained by the simulation, the longest thermal time constant found is $\tau=9.1 \mu \mathrm{s}$. The two-time constants simulated and calculated exhibit approximately the same value.

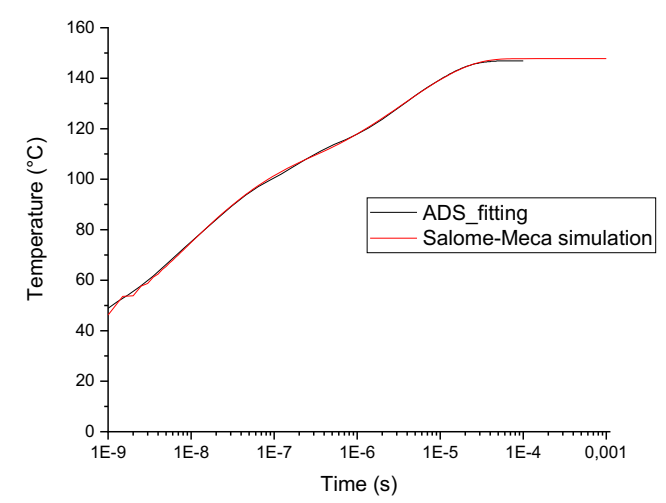

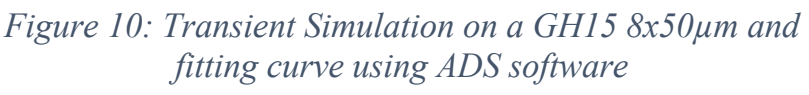

\section{SUMMARY AND DISCUSSION}

Good agreement is found between the thermoreflectance method that measures the surface temperature, and the electrical methods that measures the average temperature in the channel. Normally those temperatures should be different but in fact they are very close. Several elements can be considered to justify this result:

On one hand, the measured channel temperature is an average temperature that is lower than the maximum temperature

On the other hand, the surface temperature is measured at the end of the fingers due to air bridges so the measured temperature is also lower than the maximum surface Last element, the use of the $365 \mathrm{~nm}$ wavelength allow to measure temperature through the SiN layer, so close to the cap layer. So, the measured "surface" temperature is not really a surface temperature.

For the thermal time constant, the simple formula given in [2] and the results of the $3 \mathrm{D}$ simulation gives approximately the same value, but for the optical measurements we found a difference of $30 \mu \mathrm{s}$. This difference can be explained by the width of LED pulse which is probably to large to be accurate enough. The discrepancy between the experimental time constant and the theoretical one obtained with a 1-D approximation requires further investigation

\begin{tabular}{|l|l|l|l|l|}
\hline $\begin{array}{l}\text { GH15 } \\
8 \times 50 \mu \mathrm{m} \\
6 \times 50 \mu \mathrm{m}\end{array}$ & TR & $\begin{array}{l}\text { 3D } \\
\text { simulation }\end{array}$ & $\begin{array}{l}\text { Bagnall } \\
\text { equation }\end{array}$ & $\begin{array}{l}\text { Pulsed } \\
\mathrm{I}-\mathrm{V}\end{array}$ \\
\hline $\begin{array}{l}\text { Thermal } \\
\text { resistance } \\
\mathrm{R}_{\mathrm{th}}\left({ }^{\circ} \mathrm{C} / \mathrm{W}\right)\end{array}$ & $\begin{array}{l}31.4- \\
42.86\end{array}$ & $30.7-42.8$ & $\begin{array}{l}32.5- \\
41.25\end{array}$ \\
\hline $\begin{array}{l}\text { Thermal } \\
\text { time } \\
\text { constant } \\
(\mu \mathrm{s})\end{array}$ & 40 & 9.1 & 10.9 & \\
\hline
\end{tabular}

Table 2: Comparison of the results of GaN HEMT transistor $8 \times 50 \mu \mathrm{m}$ in black and 6x50um in red

\section{CONCLUSION}

In this work, we have cross-validated the static thermoreflectance approach with an electrical approach and compared the thermal time constant obtained using both thermoreflectance approach and simulation values. Results obtained for $6 \times 50$ and $8 \times 50$ reveal a good scaling rule concerning the thermal resistance ratio.

\section{ACKNOWLEDGMENT}

The Special thanks to UMS for providing the GH15 transistors and ANR-17- ASTR-0007-01 (COMPACT project)

\section{REFERENCES}

[1] G. Mouginot, R. Sommet, R. Quéré, Z. Ouarch; S. Heckmann, M. Camiade, "Thermal and trapping phenomena assessment on AlGaN/GaN microwave power transistor," Microwave Integrated Circuits Conference (EuMIC), 2010 European, pp. 110-113, Sept 2010

[2] K. R. Bagnall and E. N. Wang, "Theory of Thermal Time Constants in GaN High-Electron-Mobility Transistors," in IEEE Transactions on Components, Packaging and Manufacturing Technology, vol. 8, no. 4, pp. 606-620, April 2018.

[3] Kendig, D., G. Pavlidis, S. Graham, Justin Reiter, M. Gurr, D. Altman, Stephen Huerster and A. Shakouri. "UV Thermal Imaging of RF GaN Devices with GaN Resistor Validation.” 2018 91st ARFTG Microwave Measurement Conference (ARFTG) (2018): 1-4.

[4] G. Pavlidis et al., "Thermal Performance of GaN/Si HEMTs Using Near-Bandgap Thermoreflectance Imaging," in IEEE Transactions on Electron Devices, vol. 67, no. 3, pp. 822-827, March 2020.

[5] M. Bouslama et al., "Dynamic Performance and Characterization of Traps Using Different Measurements Techniques for the New AlGaN/GaN HEMT of 0.15- \$ \\u\$ m Ultrashort Gate Length," in IEEE Transactions on Microwave Theory and Techniques, vol. 67, no. 7, pp. 2475-2482, July 2019, doi: 10.1109/TMTT.2019.2907540.

[6] Cree, Inc., Durham, NC, USA (2011), Silicon Carbide Substrates and Epitaxy :

https://scn.cree.com_onelink_cree/en2zh/products/pdf/MATCATALOG.pdf

[7] K.Kamitani, M. Grimsditch, J. C. Nipko, C.-K. Loong, M. Okada, and I. Kimura, "The elastic constants of silicon carbide: A Brillouinscattering study of $4 \mathrm{H}$ and $6 \mathrm{H} \mathrm{SiC}$ single crystals," J. Appl. Phys., vol. 82, no. 6, pp. 3152-3154, Sep. 1997.

[8] R. Menozzi et al., "Temperature-Dependent Characterization of AlGaN/GaN HEMTs: Thermal and Source/Drain Resistances," in IEEE Transactions on Device and Materials Reliability, vol. 8, no. 2, pp. 255-264, June 2008, doi: 10.1109/TDMR.2008.918960.

[9] I. Angelov and C. Karnfelt, "Direct Extraction Techniques for Thermal Resistance of MESFET and HEMT Devices," 2007 IEEE Radio Frequency Integrated Circuits (RFIC) Symposium, 2007, pp. 351-354, doi: 10.1109/RFIC.2007.380899.

[10] M. Kuball, G. J. Riedel, J. W. Pomeroy, A. Sarua, M. J. Uren, T. Martin, K. P. Hilton, J. O. Maclean, and D. J. Wallis, "Time-resolved temperature measurement of $\mathrm{AlGaN} / \mathrm{GaN}$ electronic devices using micro-Raman spectroscopy," IEEE Electron Device Lett., vol. 28, no. 2, pp. 86-89, Feb. 2007 